\title{
COMPARISON OF VOLUME AND FREQUENCY BASED FEEDING PROTOCOLS IN VERY LOW BIRTH WEIGHT INFANTS (VLBWI): A PROSPECTIVE RANDOMIZED STUDY
}

\author{
A.A. Zubani, A. Mersal, S. Alsaedi, A. Aldeek \\ Pediatrics, King Faisal Specilist Hospital and Research Center- Jeddah, Jeddah, Saudi Arabia
}

Introduction: Optimal approach of enteral feeding in VLBWI has yet to be established.

Objective: To compare two strategies for advancement of feeding in VLBWI. Primary outcome was total days required to reach full feeding without necrotizing entercolitis (NEC), secondary outcomes included weight gain at the end of the feeding protocol and the length of hospital stay.

Methods: A prospective randomized, study in a tertiary center was conducted on infants ( $<1500$ grams). 63 infants were enrolled, 52 infants $(82.5 \%)$ completed the study. Infants in Group A (frequency advancement) $\mathrm{n}=24(46.2 \%)$ started at $8 \mathrm{hrs}$ feed interval and the frequency gradually increased to every $3 \mathrm{hrs}$ interval with increase in volume by only $10 \mathrm{cc} / \mathrm{kg} /$ day. Infants in group B (volume advancement) $\mathrm{n}=28(53.8 \%$ ) were fed every $2 \mathrm{hrs}$. However, volume was incrementally increased by $15 \mathrm{cc} / \mathrm{kg} / \mathrm{day}$.

Results: The groups were comparable for gestational age and birth weight. Infants in Group B reached full feed without NEC significantly earlier than in Group A, difference about 12 days between the groups $(\mathrm{P}<$ 0.005).As secondary outcomes, the data revealed a significant difference in end of the protocol weight gain between the groups (1366g for group A vs. $1564 \mathrm{~g}$ for group $\mathrm{B} ; \mathrm{P}<0.019$ ). There were no statistical differences in the length of hospital stay in both groups $(\mathrm{P}=0.43)$.

Conclusions: Among VLBWI, incremental increase in enteral feeds by $15 \mathrm{cc} / \mathrm{kg} /$ day is a safe practice. It has not only shown to result in faster attainment of full feed but also contributes towards more weight gain. Therefore, we recommend the volume advancement protocol for feeding the VLBW infants 